\title{
The relationship between hormonal balance and growth in malnourished children and rats
}

\author{
By P. G. LUNN, R. G. WHITEHEAD, T. J. COLE AND S. AUSTIN \\ Dunn Nutrition Unit, University of Cambridge, and Medical Research Council, \\ Milton Road, Cambridge CB4 I XJ
}

(Received I6 February I978 - Accepted I9 September 1978)

\begin{abstract}
I. Plasma concentrations of insulin, cortisol and growth hormone, and growth velocities have been measured in a group of Gambian village children up to 3 years of age. All three hormones showed changes in concentration with age, as did rates of growth.

2. Plasma insulin concentrations in the children were directly correlated with velocity of growth in height and weight, whereas cortisol concentrations showed inverse relationships. The values for insulin:cortisol concentration correlated more closely with growth velocity than did either hormone individually. Growth hormone values in plasma exhibited only marginal correlations with growth in height or weight, and these were negative.

3. Similar relationships between these hormones and growth were obtained from an animal experiment in which the rates of growth of rats were altered by restricting dietary intake of protein or energy or both.

4. Possible mechanisms for these observations are discussed in the light of recent knowledge concerning the hormonal control of growth rates.
\end{abstract}

Children living in the village of Keneba in The Gambia exhibit marked faltering of growth, particularly during the second half of infancy. As judged by the standards of Stuart \& Stevenson (1954) as modified by Jelliffe (1966), the mean weight-for-age of these children has been shown to fall quickly during the first year of life, reaching about $75 \%$ at I year, at which level it remains until at least the age of 3 years. The expected height-for-age also decreases, reaching a minimum value of $88 \%$ during the third year of life (Whitehead et al. 1977).

It has been demonstrated that these abnormalities in growth performance are associated with a number of environmental constraints. Despite prolonged breast feeding up to I 8 months of age or more, a dietary deficit has been shown to occur starting between 3 and 6 months of age. At that time maternal breast milk supplies no longer satisfy all the energy requirements of the growing child (Whitehead et al. 1978) and the traditional cereal-based weaning food fails to bridge the 'energy gap' (Whitehead, 1976). At this age, too, the children are increasingly subjected to an intolerable burden of infections and infestations (McGregor et al. 1970) of which gastroenteritis and malaria have been shown to cause significant impairment of growth in weight and height (Rowland et al. 1977; Whitehead et al. 1977). Little is known, however, of the detailed mechanisms by which these different environmental factors may inhibit growth. Apart from a simple lack of nutrients it was possible that alterations in the balance of those hormones which control the rate of growth might also be important. For example, stress, particularly that associated with illness, is known to induce elevated plasma corticosteroid concentrations, which inhibit protein synthesis in skeletal tissues and consequently cause growth retardation (Catt, 1970 a). It has also been reported that severe deprivation can result in child dwarfism, and that in such children plasma growth hormone concentrations are abnormally low and do not show the usual response to various stimulation tests (Brasel, 1973; Krieger, 1973). These changes in hormone balance would interact with those arising from the diet itself; an inadequate food intake results in 
reduced plasma concentrations of insulin, and low levels of this hormone cause loss of weight and decreased growth (Catt, $1970 \mathrm{~b}$ ).

The longitudinal study into the epidemiology of malnutrition at present being conducted in The Gambia has afforded the opportunity to investigate the relationship between growth and plasma concentrations of insulin, cortisol and growth hormone more fully. A parallel investigation has also been carried out into the correlations between hormonal balance and growth in protein and energy malnourished rats.

\section{EXPERIMENT AL}

\section{Children}

The 179 children in the study were living in one of three villages - Keneba, Manduar and Kantongkunda - all of which are situated in the Kiang West region of The Gambia. They were participants in a broadly-based longitudinal study of diet and rural child health and, in addition to the collection of dietary information, the medical and nutritional status of each child was assessed at least monthly during the first 3 years of life (Whitehead et al. 1977). Regular routine and sick-children clinics were held and appropriate medical therapy given whenever required. Routine blood samples for monitoring of haemoglobin levels and screening for malarial parasites were taken at monthly intervals and plasma was available for hormone assays. Blood was collected between 08.00 and 10.00 hours into heparinized tubes and since it is not the custom to eat breakfast, the samples can be regarded as essentially fasting ones. The plasma for hormonal assay was deepfrozen and flown to the Dunn Nutritional Laboratory in Cambridge, UK, where it was stored at $-20^{\circ}$ until analysed. Weight was measured using baby-weighing scales (Todd's Scale Works, Cambridge) and supine length using a Harpenden stadiometer (Holtain Ltd, Dyfed).

The results presented in this paper were collected over a 9-month period. Ages at the start of the study ranged from 3 months to over 2 years, and almost all children completed the full course of the investigation.

\section{Animals}

Male rats from the Dunn Nutritional Laboratory strain of specific-pathogen-free hooded rats were used in the experiment. The three diets used were as described by Coward et al. (1977), with protein:energy (P:E) values of $0.21,0.032$ and 0.005 . Animals were weaned at 3 weeks of age onto the high-protein-containing diet on which they were maintained for 2 weeks. At this time they were weighed, and forty-two rats randomly allocated to each of the three diets. Seven animals on each diet were fed ad lib. but the food consumption of the other groups of seven was restricted such that they consumed $90,80,70,60$ and $50 \%$ of the mean intakes ( $\mathrm{g} / \mathrm{kg}$ body-weight) of the rats fed on the respective diets $a d \mathrm{lib}$. This rather complicated dietary procedure arose because the rats were also part of another more extensive experiment into protein-energy malnutrition.

After 2 weeks the animals were weighed, then killed by exsanguination under diethyl ether anaesthesia and their plasma was stored at $-20^{\circ}$ before analysis.

\section{Analytical methods}

Plasma corticosterone in rats was measured using a competitive protein-binding method (Lunn et al. 1976). Plasma cortisol in the children was measured by a similar procedure except that the corticosteroid-binding globulin reagent contained $10 \mathrm{ml}$ rabbit serum plus $50 \mu \mathrm{Ci}\left[{ }^{3} \mathrm{H}\right]$ cortisol in $110.05 \mathrm{M}$-phosphosaline buffer, $\mathrm{pH} 7.4$, and cortisol standards were used.

Insulin was estimated by the method C of Hales \& Randle (1963) with reagents supplied 
in kit form by the Radiochemical Centre, Amersham, Bucks., and using a standard preparation of human insulin from Wellcome Reagents Ltd, Beckenham, Kent. In the analysis of plasma samples from the children, the use of the kits differed from that recommended by the manufacturers in that standards in the range $0-10 \mu \mathrm{U} / \mathrm{ml}$ were introduced, the concentration of insulin-binding reagent was decreased by $50 \%$ compared to the recommended level, and the incubation period increased. These modifications gave a greater sensitivity over the low range in which most of the values were found.

Human growth hormone measurements were carried out by the double-antibody radioimmunoassay method of Molinatti et al. (1969) with materials produced in kit form by CEA-IRE-SORIN supplied by Eurotope Services Ltd, New Barnet, and using a human growth hormone standard prepared at the Clinical Physiology Laboratory of the National Research Council, Pisa, Italy.

Rat growth hormone concentrations were assayed by a double-antibody radioimmunoassay technique using materials supplied by the NIAMDD rat pituitary hormone distribution programme (Lunn \& Austin, unpublished results).

\section{RESULTS}

\section{Children}

The mean monthly growth velocities for both height and weight of the Gambian village children are shown in Fig. I $(a, b)$, where they are compared with comparable values calculated from the standards of Stuart \& Stevenson (1954) as modified by Jelliffe (1966).

Height growth was well below the standard even during early infancy, and this deficit became more marked in the second year. Throughout the first 2 years the mean rate of growth in height was only about $60 \%$ of normal. The rate improved to equal the standard, however, during the third year of life.

With weight gain, the most marked faltering occurred during the first year, particularly in the $0.6-1.0$ year period, when the mean growth of the children was only about $11 \%$ of that expected. During the second year the children still only averaged about $45 \%$ of the standard rate but then, as with height growth, there was some improvement during the third year.

The corresponding changes in mean plasma concentrations of cortisol, insulin and growth hormone are summarized in Fig. 2. Plasma insulin concentrations up to 6 months of age were about the expected value, but decreased sharply after this period, reaching a minimum between 12-15 months of age. In contrast, mean cortisol and growth hormone concentrations both increased until the middle of the second year of life, but from then onwards decreased to values considered normal for children of this age (Lunn et al. 1973).

\section{Plasma hormone concentration and growth}

Preliminary analysis of the hormone concentrations showed them to have markedly skew distributions, with standard deviations increasing in step with the mean. For these reasons the hormone values were transformed to their logarithms prior to further analysis. Heights and weights have been analysed untransformed.

For each child, a regression line $v$. time was fitted through the individual heights and weights to give estimates of height and weight gain per month over the period studied. The log concentrations of insulin, cortisol and growth hormone were averaged over all the samples from each individual. The following correlations were then observed between these measurements.

Insulin. Although plasma insulin concentration did correlate with weight velocity $(r 0.30$, $P<0.001)$, a closer relationship was observed with height velocity $(r 0.53, P<0.001)$. 

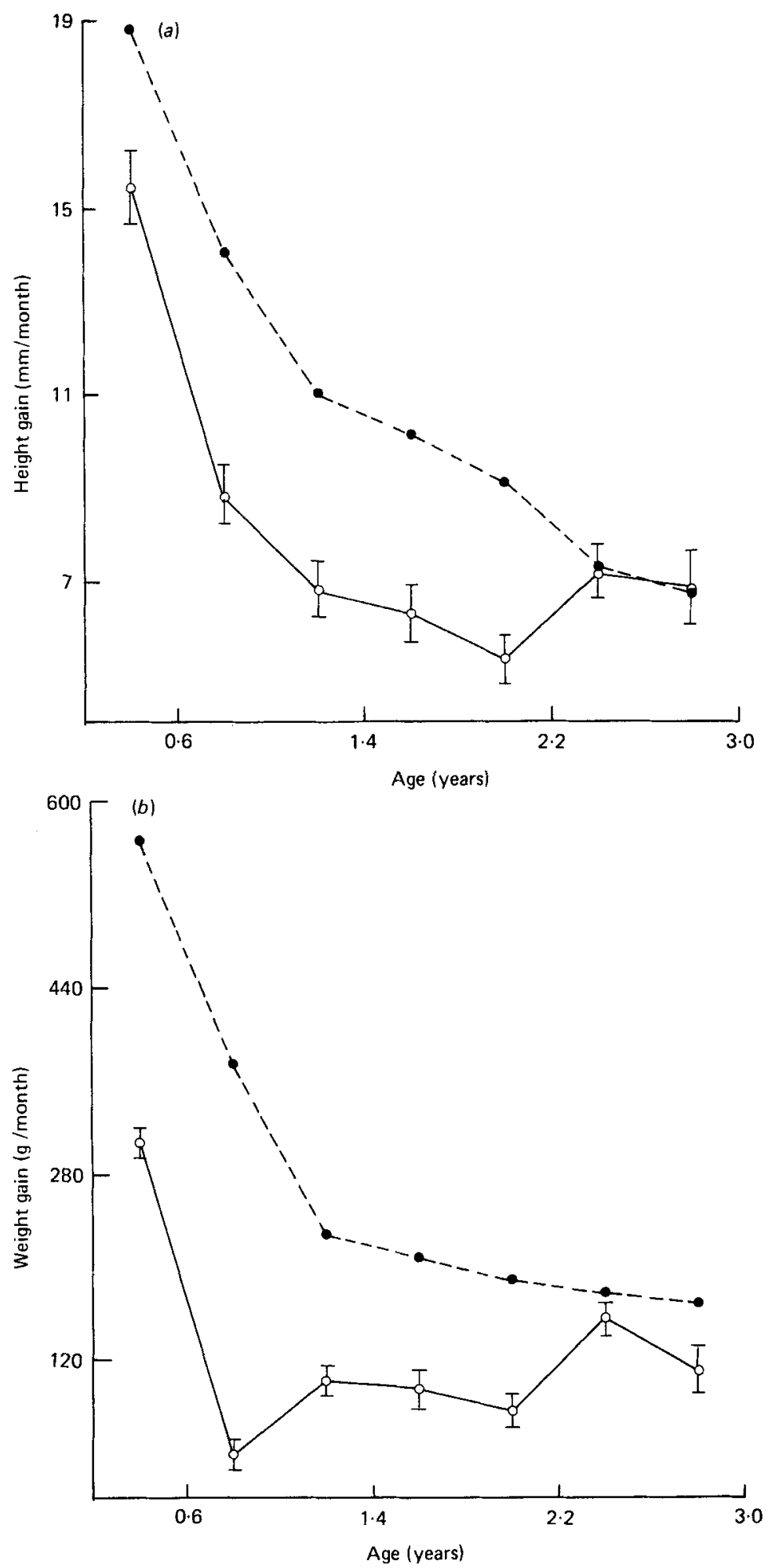

Fig. 1. Velocities of growth in height and weight of Gambian village children compared with corresponding values calculated from the standards of Stuart \& Stevenson (1954) as modified by Jelliffe (1966). $\bigcirc-O$, Gambian children (mean values with standard errors represented as vertical bars); --0 , standard results. 


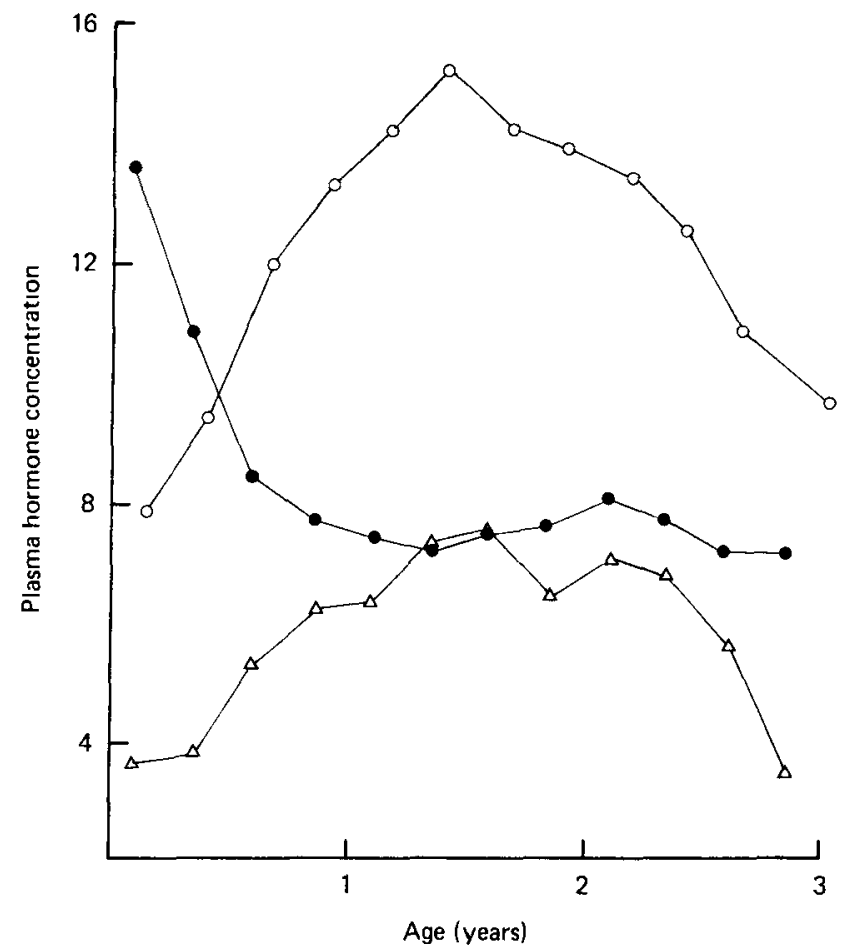

Fig. 2. Variations with age (years) of plasma concentrations of insulin $(\mu \mathrm{U} / \mathrm{ml})(-<)$, cortisol $(\mu \mathrm{g} / \mathrm{l})(\mathrm{O}-\mathrm{O})$ and growth hormone $(\mathrm{ng} / \mathrm{ml})(\triangle-\triangle)$ in Gambian village children (for details, see p. 73). Standard errors (which averaged \pm 0.5 units for each point) are not shown for reasons of clarity.

This relationship is shown in Fig. 3; the higher the insulin concentration, the faster the children were growing.

Cortisol. The cortisol results contrasted with those for insulin in that there was a negative correlation with growth. As for insulin, this was more marked with growth in height ( $r 0.5 \mathrm{I}, P<0.001)$ than in weight $(r 0.34, P<0.00 \mathrm{I})$. The result with height gain is shown in Fig. 4 .

Insulin and cortisol have directly opposite metabolic effects as regards protein metabolism, and it is therefore reasonable to suppose that it is the balance between these hormone concentrations which is the important factor. Values for insulin:cortisol concentration were therefore calculated and compared against growth. As predicted, the inclusion of both hormones as a ratio gave significantly stronger correlations $(P<0.00 \mathrm{I})$ than

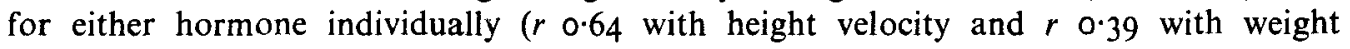
velocity, both $P<0.001$ ). The correlation of insulin: cortisol $v$. height gain is shown in Fig. 5.

Growth hormone. The relationship between this hormone and growth was much less marked than for either insulin or cortisol, and there was a negative correlation with both height gain $(r-0.33, P<0.001)$ and weight gain $(r-0.32, P<0.001)$.

Age standardization. The preceding analysis indicates that in general children with a high insulin:cortisol value grow faster than those with lower values. However, it is clear from Figs. I and 2 that the lowest plasma cortisol and the highest insulin concentrations are seen in the youngest children, who as one would expect are those with the faster rates of growth. 


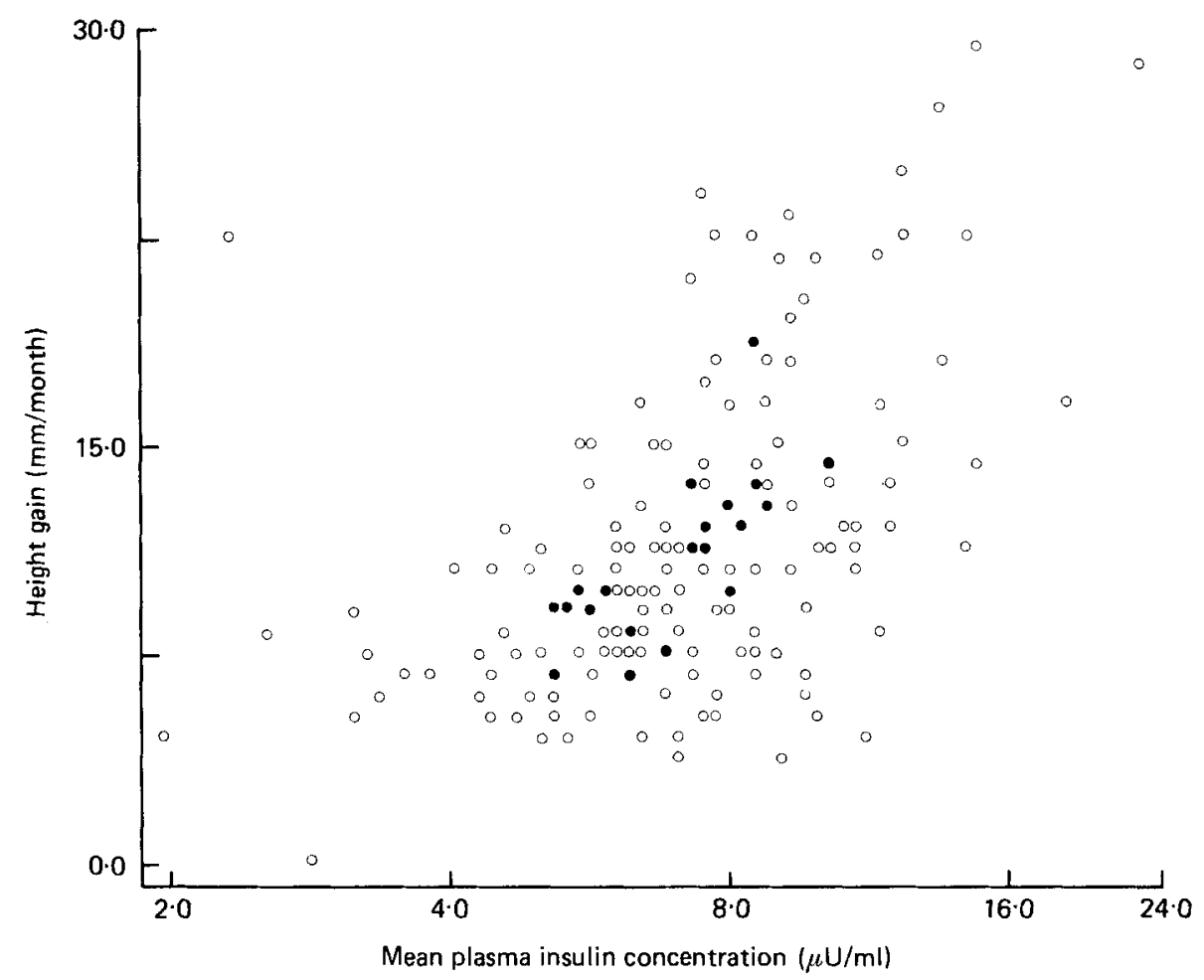

Fig. 3. Relationship between the velocity of growth in height ( $\mathrm{mm} / \mathrm{month})$ and plasma insulin concentrations $(\mu \mathrm{U} / \mathrm{ml})$ in Gambian village children (for details, see p. 75 ). (O), Two or more coincident points.

Consequently it was important to know to what extent age had contributed to the correlations shown in Figs. 3-5.

This was established using multiple regression analysis, with each child's mean growth rate as the dependent variable. Due to the shape of the growth curve, the effect of the variation in age of the children was removed by fitting a quadratic equation in age, computed for each child as the age at the mid-point of their time in the study. The hormone effect was included simultaneously as the third variable. This procedure confirmed that some of the growth rate $v$. hormone correlation was accounted for by changes of these two parameters with age. However, there remained highly significant partial correlations between height gain and insulin, cortisol and insulin: cortisol $(P<0.001)$, showing that the relationships described do hold after standardizing for age.

Similar treatment of the weight velocity values demonstrated that cortisol and insulin: cortisol remained significantly correlated $(P<0.05)$, but not insulin $(P<0.1)$. After age standardization, growth hormone showed only a marginal negative correlation with height gain $(P<0.05)$, but was more strongly related to weight gain $(P<0.01)$.

\section{Rats}

The change in body-weight of the rats fed for 2 weeks on the dietary regimens described ranged from $+98 \mathrm{~g}$ on the higher-protein diet fed $a d$ lib. to $-30 \mathrm{~g}$ on the lowest-protein diet fed at $50 \%$ restriction. The concentrations of insulin and corticosteroids changed in a way similar to that observed in the children, insulin being highest and corticosterone lowest in the fastest growing rats. 


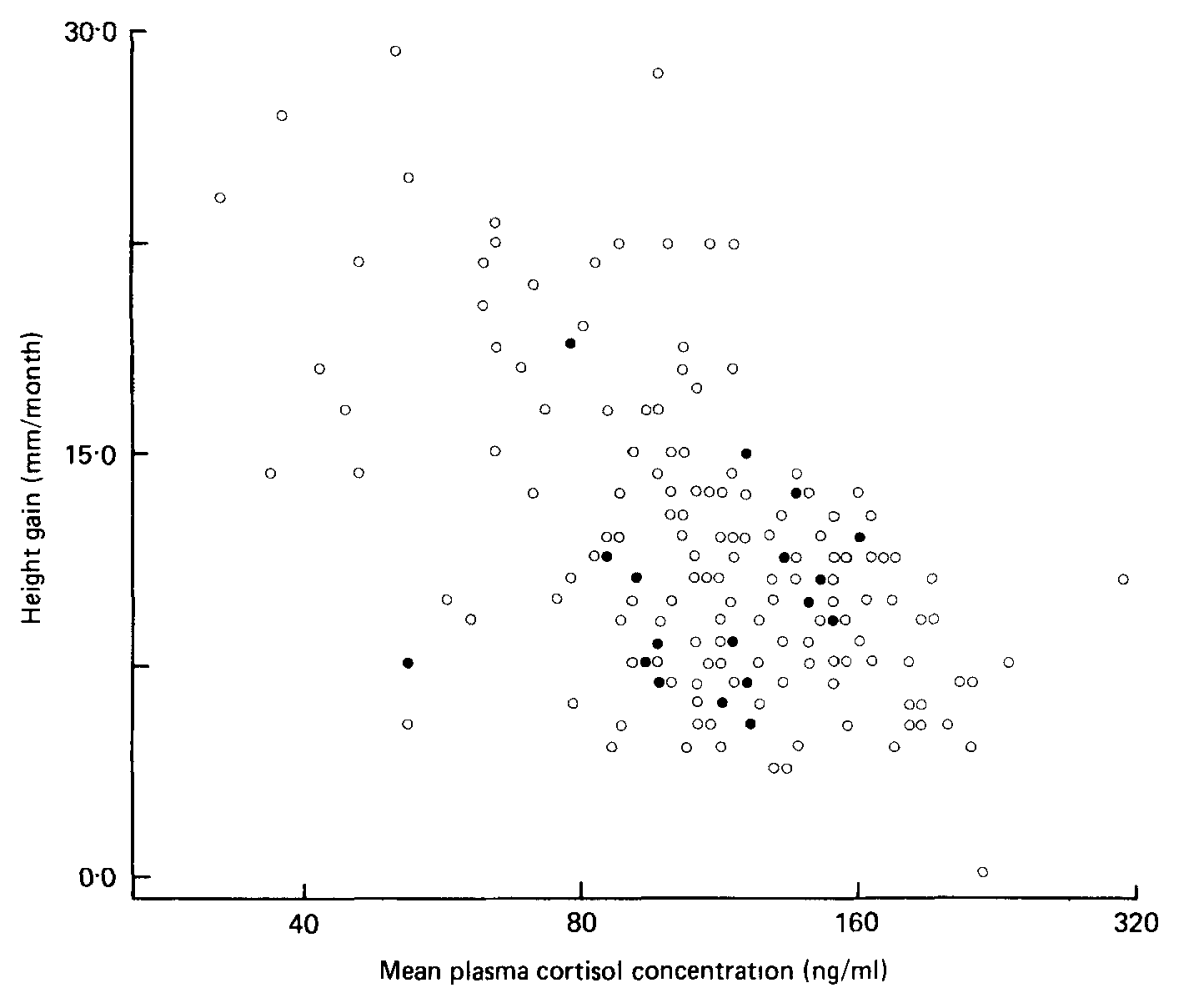

Fig. 4. Relationship between the velocity of growth in height ( $\mathrm{mm} / \mathrm{month}$ ) and plasma cortisol concentration ( $\mathrm{ng} / \mathrm{ml}$ ) in Gambian village children (for details, see p. 77). (๑), Two or more coincident points.

The rates of growth in weight were compared with the corresponding plasma concentrations of these hormones in a similar way to the 'child' results, and are shown in Figs. 6-8. Both insulin $(r 0.8 \mathrm{I}, P<0.00 \mathrm{I})$, and corticosterone $(r-0.62, P<0.00 \mathrm{I})$, were correlated with weight gain, but the strongest relationship was again between growth and insulinglucocorticoid $(r 0.84, P<0.00 \mathrm{I})$. Plasma growth hormone concentrations showed only a marginally significant correlation with the rate of weight gain $(r 0.26, P<0.05)$. It differed from the results obtained from children in that the relationship was positive.

\section{DISCUSSION}

The wide range of plasma hormone concentrations which were observed during the first 3 years of life in rural Gambian children must be considered in the light of the huge burden of infection experienced, as well as the dietary inadequacies. For example, increased plasma cortisol concentrations are known to occur in association with many infections. The particular importance of gastroenteritis in relation to growth faltering in Gambian children has been demonstrated by Rowland et al. (I977). Anorexia, nutrient loss due to diarrhoea and vomiting and a consequent tendency towards low blood glucose concentrations, might be expected to increase glucocorticoid output. Likewise plasma insulin concentrations are probably decreased partly for the same reasons and also because of the rather low energy intake of the children (Whitehead et al. 1977). The cause of the growth hormone changes is more obscure. The over-all pattern of change with age is very much like that of cortisol, 


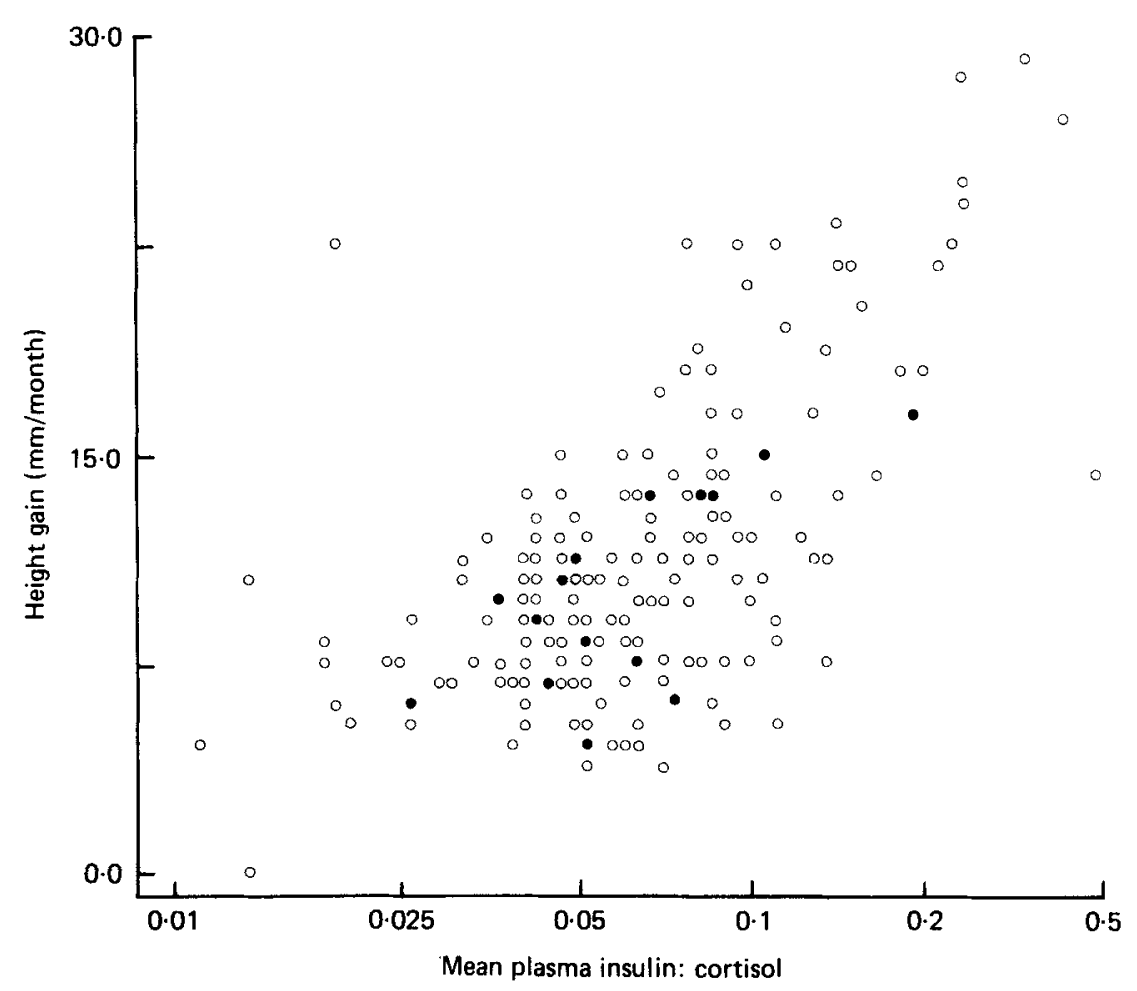

Fig. 5. Relationship between the velocity of growth in height $(\mathrm{mm} / \mathrm{month})$ and plasma insulin: cortisol concentrations (plasma insulin concentration $(\mu \mathrm{U} / \mathrm{ml})$ :plasma cortisol concentration $(\mu \mathrm{g} / \mathrm{l})$ in Gambian village children (for details, see p. 77). (O), Two or more coincident points.

and may be due to similar stimuli; stress and hypoglycaemia. Alternatively, it is possible that it is a response to the severe height and weight deficit of these children. Plasma growth hormone concentrations have, for example, been shown to be very high in the severelyunderweight Laron dwarf (Laron et al. 1968).

Regardless of the adequacy of the diet, children with such hormonal patterns would be expected to exhibit abnormal growth and development. In this paper, it has been shown that plasma insulin concentrations were positively, and cortisol negatively correlated with growth in both height and weight. Also, that plasma insulin:cortisol was more strongly correlated with growth rates than either hormone alone. In contrast growth hormone concentration showed only a weak and negative relationship with the rate of growth of the village children. Similar results for insulin and cortiscosterone were obtained from the rat experiment, but there growth hormone showed a weak positive correlation with weight gain.

The results suggest that the adverse environmental conditions affecting the Keneba village children, i.e. the synergistic effects of the nutrition-infection interaction, do exert their effects on growth rates partially via alterations in the pattern of plasma hormone concentrations. The similarity of the hormonal patterns with those seen in disease-free rats could be interpreted as an indication that some changes at least were primarily related to nutrition and growth rather than to the spectrum of infectious phenomena.

The present results are in accord with the suggestion made by Laron et al. (1972) that the concentration of plasma insulin rather than growth hormone correlates best with growth. More recently Daughaday, et al. (1976) have also come to similar conclusions. The present 


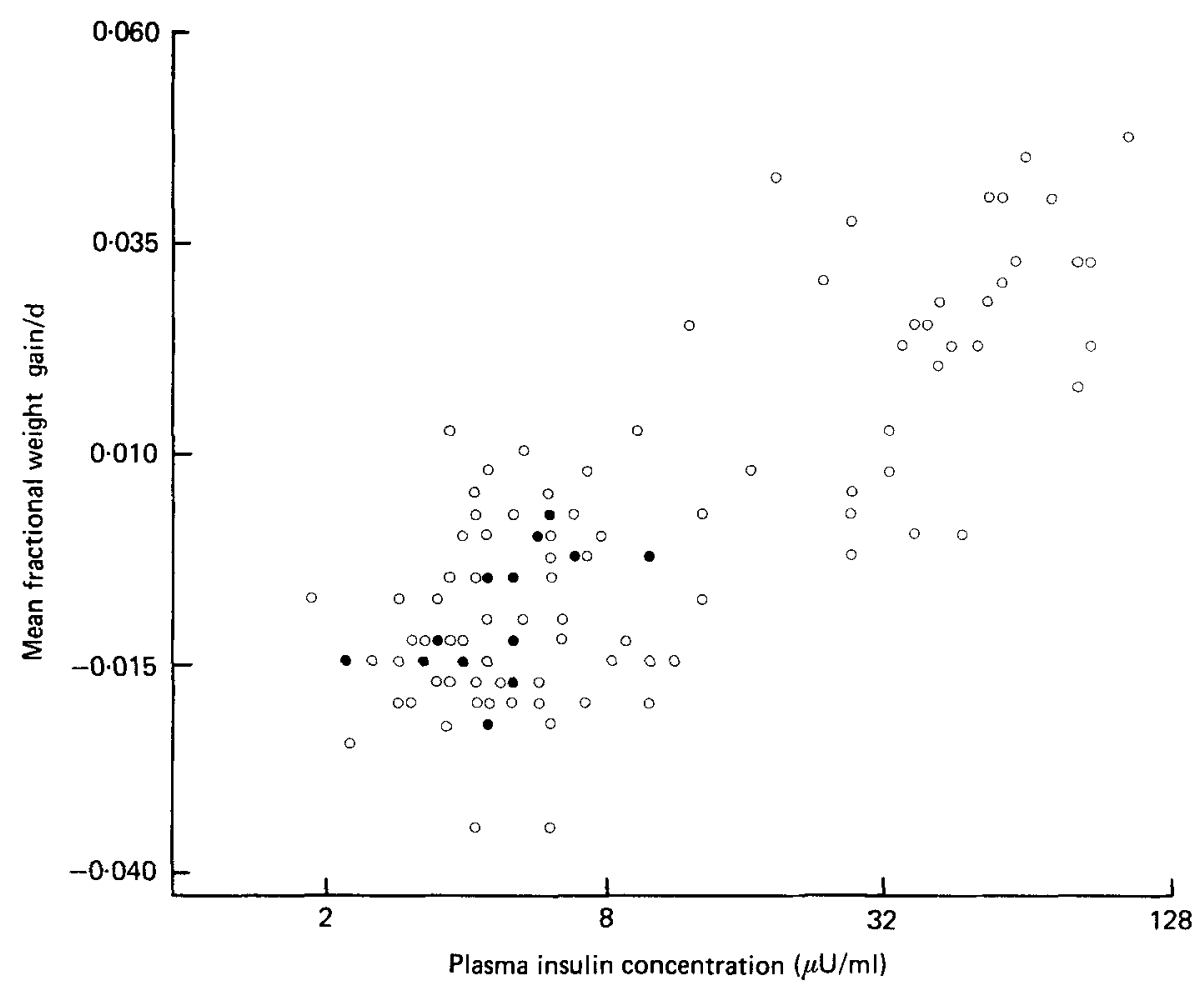

Fig. 6. Relationship between velocity of weight gain $(/ d)$ and plasma insulin concentrations $(\mu \mathrm{U} / \mathrm{ml}$ ) in malnourished rats (for details, see p. 78 ). (O), Two or more coincident points.

results, however, are perhaps of greater physiological relevance in that they have been obtained from typical rural village children leading their normal lives, not from patients with gross endocrinological abnormalities. The similar results obtained from the experimentally-malnourished rats confirm the 'child' results.

The mechanisms by which hormones affect growth even in healthy children are complex. Growth occurs by both hypertrophy and hyperplasia, and in children of the age studied both processes should be active, with hyperplasia probably being the more important (Cheek, 1972). Growth hormone appears to be essential for this process, and a total lack of this hormone results in severe dwarfing. Insulin and cortisol, however, are known to modify the effectiveness of growth hormone in promoting hyperplasia, insulin causing an increase in efficiency (Laron et al. 1972), and cortisol resulting in a decrease (Goldberg \& Goldspink, 1975; Loeb, 1976). It seems unlikely that high concentrations of glucocorticoids such as those found in some Gambian children have retarded growth by inhibiting growth hormone release, as it has been shown that children treated for long periods with high levels of corticosteroids still exhibit a normal response to arginine or insulin stimulation tests, even though growth has been retarded (Morris et al. I968; Root et al. I969; Rappaport et al. 1973). The concomitant increase in plasma cortisol and growth hormone concentration in the Gambian children is therefore not metabolically incompatible.

Somatomedin plays a central role in growth metabolism, and recently it has been suggested that insulin and cortisol can both affect the rate of somatomedin generation by the liver. In perfused rat liver preparations, insulin has been shown to act synergistically with growth hormone in the stimulation of somatomedin production (Daughaday et al. 1976). 


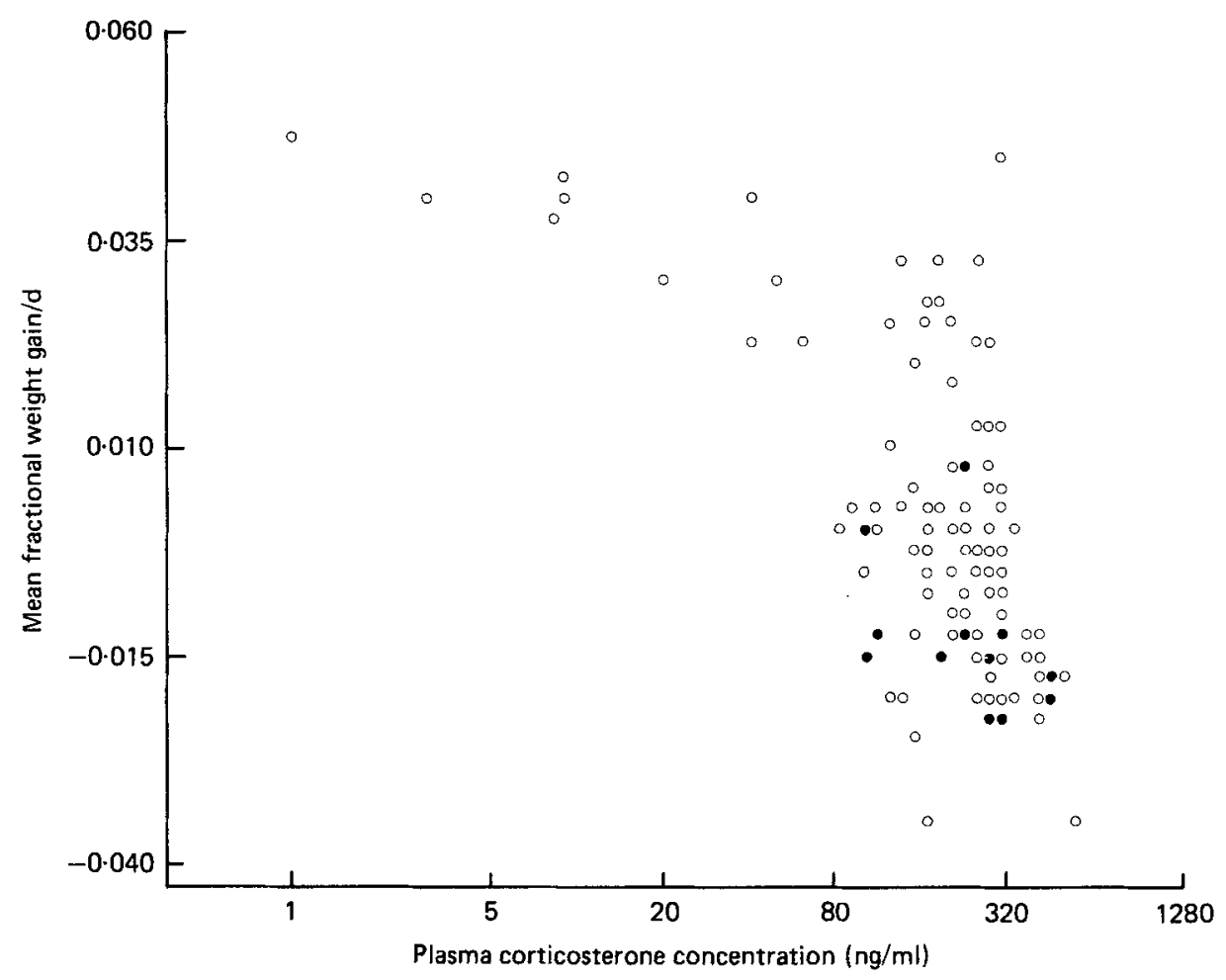

Fig. 7. Relationship between velocity of weight gain (/d) and plasma corticosterone concentration (ng/ml) in malnourished rats (for details, see p. 79). (O), Two or more coincident points.

In contrast, children treated with corticosteroids had low serum somatomedin levels despite normal or increased growth hormone concentrations (Elders et al. 1975), and it seems likely that this is due to an inhibition of somatomedin generation (Phillips, et al. 1973). It is unfortunate that extensive assays for somatomedin have not yet been possible in the rural Gambian children. However, in a few assays that were performed using the embryonic chick pelvic girdle technique (Hall, 1972), values were low and particularly so in the hospitalized children with severe marasmus; concentrations also increased with dietary therapy. Unfortunately, the physiological interpretation of these findings is not straightforward, as Froesch et al. (1976) have recently shown that assays of this type are susceptible to interference by a variety of other serum constituents. The somatomedin assays in South African cases of severe kwashiorkor, which also resulted in low values, were measured using a similar bioassay technique (Grant et al. 1973). A radio-receptor assay for somatomedins $A$ and $C$ has now been developed (Van Wyk et al. 1975) and it is hoped shortly to assess the concentration of these hormones in the village children by this direct method.

The authors wish to acknowledge the valuable assistance of Dr M. G. M. Rowland, who collected the blood samples, and of Dr and Mrs J. B. Mason for the height and weight measurements made on the Gambian children. 


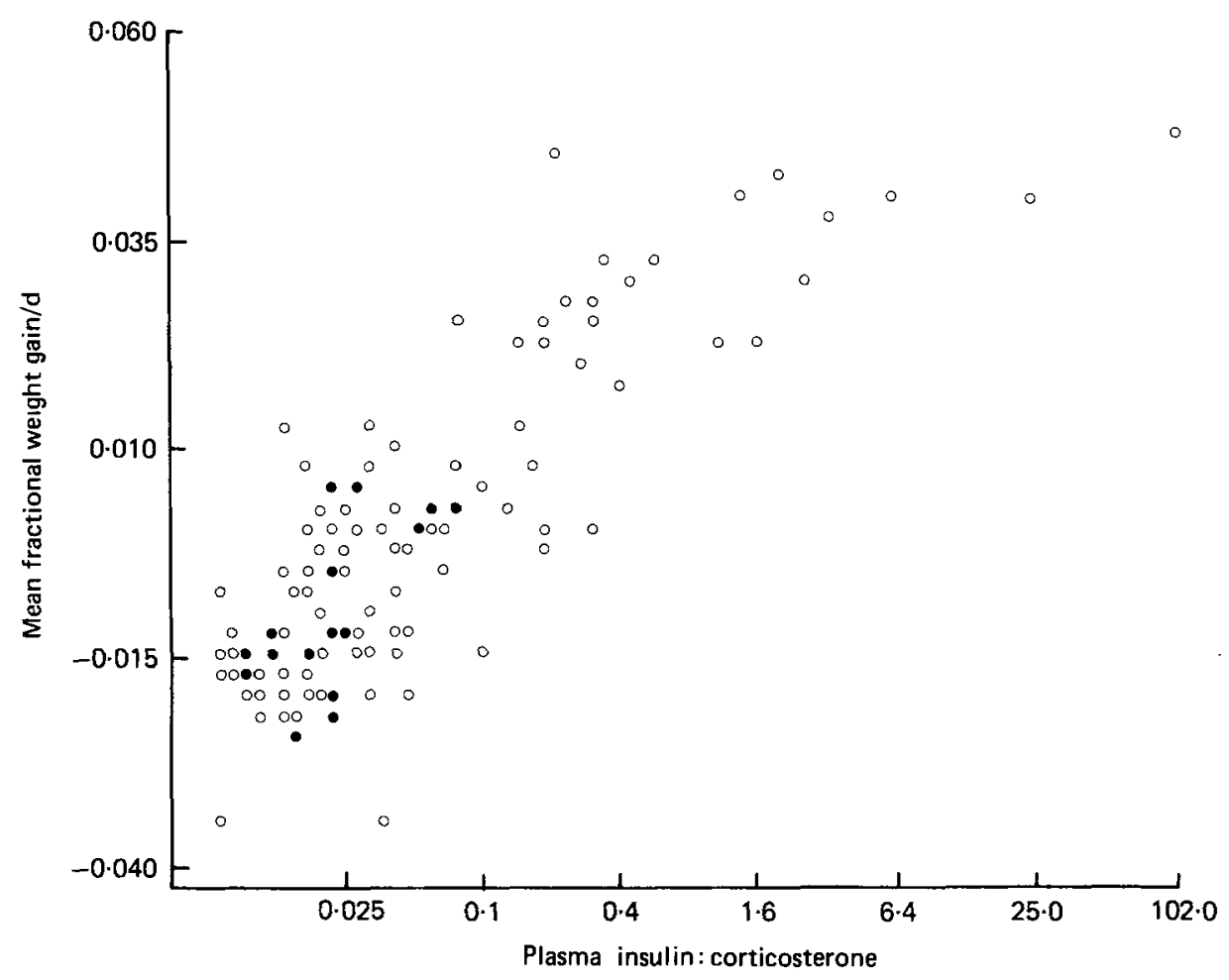

Fig. 8. Relationship between velocity of weight gain (/d) and plasma insulin:corticosterone concentration (plasma insulin concentration $(\mu \mathrm{U} / \mathrm{ml})$ : plasma corticosterone concentration $(\mu \mathrm{g} / \mathrm{l})$ ) in malnourished rats (for details, see p. 79). (O), Two or more coincident points.

\section{REFER ENCES}

Brasel, J. A. (1973). In Endocrine Aspects of Malnutrition. Kroc Foundation Symposia No. I, p. I1 5 (L. I. Gardner and P. Amacher, editors). California: Kroc Foundation.

Catt, K. J. (1970a). Lancet i, I273.

Catt, K. J. (1970b). Lancet ii, 353.

Cheek, P. B. (1972). In Human Growth, p. 337 (P. B. Cheek, editor). Philadelphia: Lea and Febiger.

Coward, W. A., Whitehead, R. G. \& Lunn, P. G. (1977). Br. J. Nutr. 38, i 5.

Daughaday, W. J., Phillips, L. S. \& Mueller, M. C. (I976). Endocrinology 98, I 2 I4.

Elders, M. J., Wingfield, B. S., McNatt, M. L., Lee, J. A. \& Hughes, E. R. (1975). Am. J. dis. Childh. 129, I 393.

Froesch, E. R., Zapf, J., Audhya, T. K., Ben Porath, E., Segen, J. B. \& Gibson, K. D. (1976). Proc. Nain. Acad. Sci. U.S.A. 73, 1904.

Goldberg, A. L. \& Goldspink, D. F. (I975). Am. J. Physiol. 228, 310.

Grant, D. B., Hambley, J., Becker, D. \& Pimstone, B. L. (1973). Archs dis. Childh. 48, 596.

Hales, C. N. \& Randle, P. J. (1963). Biochem. J. 88, 137.

Hall, K. (1972). Acta endocr. Suppl. 163, 1053.

Jelliffe, D. B. (1966). Wld Hlth. Orgn. Monogr. Ser. no. 53, p. 27 I.

Krieger, I. (1973). In Endocrine Aspects of Malnutrition. Kroc Foundation Symposia No. I, p. I 29 (L. I. Gardner and P. Amacher, editors). California: Kroc Foundation.

Laron, Z., Karp, M., Pertzelan, A. \& Kauli, R. (1972). Israel. J. med. Sci. 8, 440.

Laron, Z., Pertzelan, A. \& Karp, M. (1968). Israel. J. med. Sci. 4, 883.

Loeb, J. N. (1976). New Engl. J, med. 295, 547.

Lunn, P. G., Whitehead, R. G., Baker, B. A. \& Austin, S. (1976). Br. J. Nutr. 36, 537.

Lunn, P. G., Whitehead, R. G., Hay, R. W. \& Baker, B. A. (I973). Br. J. Nutr. 29, 399.

McGregor, I. A., Rahman, A. K., Thomson, A. M., Billewicz, W. Z. \& Thompson, B. (1970). Trans. R. Soc. trop. Med. Hyg. 64, 48 . 
Molinatti, G. M., Massara, F., Strumia, E., Pennisi, F., Scasellati, G. A. \& Vancheri, L. (1969). J. nucl. Biol. Med. 13, 1 .

Morris, H. G., Jørgensen, J. R. \& Jenkins, S. A. (1968). J. clin. Invest. 47, 427.

Phillips, L. S., Herington, A. C. \& Daughaday, W. H. (1973). Endocrinology 97, 780.

Rappaport, R., Bouthreuil, E., Marti-Henneberg, C. \& Basmaciogullari, A. (1973). Acta paed. Scand. 62, SI3.

Root, A. W., Bongiovanni, A. M. \& Eberlein, R. (1969). J. Paediat. 75, 826.

Rowland, M. G. M., Cole, T. J. \& Whitehead, R. G. (1977). Br. J. Nutr. 37, 44I.

Stuart, H. C. \& Stevenson, S. S. (I954). In Textbook of Pediatrics, 8th ed., p. 48 (W. E. Nelson, editor). Philadelphia: Saunders.

Van Wyk, J. J., Underwood, L. E., Baseman, J. B., Hinty, R. L., Clemmons, D. R. \& Marshall, R. N. (1975). In Advances in Metabolic Disorders, vol. 8, p. I27 (R. Luft \& K. Hall, editors). New York, San Francisco, London: Academic Press.

Whitehead, R. G. (1976). Lancet ii, II92.

Whitehead, R. G., Coward, W. A., Lunn, P. G. \& Rutishauser, I. H. E. (1977). Trans. Roy. Soc. trop. Med Hyg. 7x, 189 .

Whitehead, R. G., Rowland, M. G. M., Hutton, M., Prentice, A. M., Müller, E. \& Paul A. (1978). Lancet ii, 178 . 